\title{
Semiocapitalismo e mídia na modulação das afecções: \\ de McLuhan a Todd Gitlin
}

\author{
Guilherme Nery Atem ${ }^{1}$
}

\section{Resumo}

Este artigo procura correlacionar as principais idéias de dois autores contemporâneos a respeito da nossa cultura audiovisual, promovida pelas mídias: Marshall McLuhan e Todd Gitlin. Inserida no contexto do Capitalismo Semiótico (Semiocapitalismo), a cultura midiatizada pode ser pensada como "forma", mais do que como "conteúdo". Os fluxos ou torrentes audiovisuais nos embalam cotidianamente, e isso traz certas reconfigurações subjetivas. Hoje, comunicar é mais importante do que os fatos comunicados. O objetivo do artigo é ensaiar questionamentos sobre a "forma-mídia", ou "império dos significantes", aspecto central nas obras desses dois autores.

Palavras-Chaves: Semiocapitalismo; mídias; modulações; afecções.

\section{Abstract}

This article intents to associate the leader thoughts from two contemporary authors about our audiovisual culture, produced by the media: Marshall McLuhan and Todd Gitlin. Inserted on context of Semiotic Capitalism (Semiocapitalism), the media culture may be understood as "form", more than "content". The flux or audiovisual waves support us every day, and this brings some subjective reconfigurations. Today, to communicate is more important than facts communicated. The finality of this article is to try asking about the "form-midium", or "empire of signifiants", central aspect in the books of both authors.

Keywords: Semiocapitalism; media; modulations; afections. 


\section{Introdução}

O presente artigo é um ensaio que procura traçar mais do que um paralelo, mas uma continuidade mesmo entre as teorias culturais e comunicacionais do canadense Marshall McLuhan (décadas de 60, 70 e 80) e do norte-americano Todd Gitlin (hoje). A relevância de tal abordagem se mostra cotidianamente: a cada segundo somos abordados por uma torrente audiovisual, por um intenso fluxo de significantes (cujos significados pouco importam).

McLuhan pensou mais a "forma" midiática do que seus conteúdos latentes, quando afirmou que "os meios são as mensagens". Adorado e odiado, o pensador canadense nos deixou uma série de questões para serem pensadas. Gitlin faz o mesmo hoje, a partir do pensamento mcluhaniano, embora recorrendo à potência analítica da Teoria Crítica.

Informações audiovisuais não se limitam a "representar" a realidade do mundo. Elas não apenas “indicam" (como índices semióticos), elas de fato "são" - têm uma realidade objetiva, além da óbvia realidade subjetiva. São presenças envolventes. As mídias são "ocasiões para experiências”, como diz Gitlin “experiências que são, em si, os principais produtos, as principais transações, os principais 'efeitos' das mídias" (GITLIN, 2003: 20).

A cada instante que passa, nos vemos mais e mais imersos na torrente das mídias, de alguma forma "conectados" ao zumbido incessante das mídias. Sua tagarelice não nos incomoda - pelo contrário.

Apesar de prometerem uma experiência de "totalidade", as imagens midiáticas seriam vestígios efêmeros, pertencentes a um tempo presente, que passa, sempre evanescente. A sensação, ao fim e ao cabo, pode ser a da “descontextualização do mundo", a da fragmentação da subjetividade. Este artigo busca pensar as mídias contemporâneas, no contexto do Semiocapitalismo (cognitivo e imaterial), como uma "instância de subjetivação e de coletivização neurológica". Sugerimos, assim, que as mídias se têm comunicado com nosso corpo. Por isso, traçamos um itinerário conceitual que vai da obra de Marshall McLuhan à de Todd Gitlin dois autores que pensam a cultura comunicacional a partir das noções de "fluxos", "torrentes", "significantes audiovisuais", "meios", "formas".

\section{Marshall McLuhan e o meio como mensagem}

Marshall McLuhan (1911-1980) é considerado o mais representativo membro da chamada Escola de Toronto, e um dos maiores teóricos da comunicação do século XX. Juntamente com outros dois grandes pesquisadores, Harold Innis e Eric Havelock, construiu uma concepção de cultura bastante própria: a cultura a partir de bases tecnológicas. 
Segundo McLuhan e seus colegas, toda cultura se define por suas bases técnicas (objetos técnicos) e tecnológicas (novas relações sociais). Os objetos técnicos são a instância de mediação entre o homem e o mundo, e o homem recorta cognitivamente o mundo em torno de si a partir da configuração tecnológica de seu tempo e lugar.

Na sua época, Marshall McLuhan começou a sofrer críticas de outros intelectuais. A principal delas era a acusação de "determinismo tecnológico". Por conta disso, McLuhan formulou sua teoria da cultura ocidental recuando às suas origens, até a oralidade arcaica. Segundo ele, a nossa cultura teria conhecido três grandes etapas, separadas por duas grandes revoluções:

1) $1^{\mathrm{a}}$ etapa: cultura oral-auditiva e tribalizada;

1.5) Revolução da prensa gráfica de Gutenberg;

2) $2^{\text {a }}$ etapa: cultura escrita-tipográfica e destribalizada;

2.5) Revolução audiovisual dos Meios de Comunicação de Massa;

3) $3^{a}$ etapa: cultura audiovisual-eletrônica e retribalizada.

A cultura oral-auditiva e tribalizada de McLuhan se divide em duas fases, segundo Pierre Lévy: a da oralidade primária (ausência de escrita) e a da oralidade secundária (complementaridade entre oralidade e escrita). As sociedades arcaicas, em suas origens, bem como muitas tribos indígenas até hoje, seriam de oralidade primária. A Grécia antiga, ou clássica, seria de oralidade secundária, como se vê bem nas suas antigas práticas políticas cotidianas (dos debates em praça pública às Constituições escritas; das aulas ao ar livre aos tratados filosóficos). A oralidade secundária teria sido a principal forma de organização da cultura até o fim da Idade Média.

Em torno de 1450, Johannes Gutenberg inventa a sua prensa gráfica de tipos móveis de metal. Sabe-se que outras formas de prensa gráfica já existiam desde o século VIII, na China e no Japão - mas não tinham tipos móveis e imprimiam ideogramas. A Alemanha de Gutenberg já conhecia as prensas de vinho. Gutenberg mesmo já havia tentado outras formas de prensa (por exemplo, de tipos em madeira), sem sucesso, antes de chegar à definitiva. As conseqüências de sua invenção ultrapassaram em muito o que se poderia prever. Segundo McLuhan, em A galáxia de Gutenberg (1962), ela se tornou uma verdadeira revolução, pois reconfigurou cada sociedade onde se popularizou.

Toda uma nova forma de cognição se formava: o "homem tipográfico" organizava agora sua intelecção em seqüência, da esquerda para a direita, de cima para baixo - como se lê. Para buscar os conteúdos, o homem precisava ler. A diferença histórica entre letrados e iletrados começava a desaparecer, pois as condições materiais do acesso aos escritos se popularizava, se barateava. Em pouco tempo, o "analfabetismo" se tornaria desvantajoso - para os indivíduos comuns, para os comerciantes, para os Estados. A cultura escrita-tipográfica 
se espalhava, tornando-se a nova mnemotécnica (externa): agora, para se conservar e memorizar a história de uma cultura, bastava registrá-la por escrito e, dependendo do caso, reproduzi-la em uma gráfica.

Todo o saber, antes privilégio de poucos monges copistas da Igreja Católica, agora se tornava público e notório. O monopólio católico do conhecimento escrito se quebrava, se pulverizava. Daí o sentido causado pela prensa de Gutenberg na Reforma Protestante de Lutero, e na nova forma de esfera pública, desde então "midiatizada".

A segunda revolução cultural, segundo Marshall McLuhan (Os meios de comunicação como extensões do homem, 1964), foi a audiovisual-eletrônica, promovida pelos Meios de Comunicação de Massa (cinema, rádio e televisão), originada na virada do século XIX para o século XX. Com a chegada dos então novos meios, uma nova revolução cultural teve lugar: aquelas novas tecnologias de comunicação reconfiguravam a cognição do até então "homem tipográfico". Este, ao invés de lidar com o conhecimento linear e sequencialmente, passava a ser impelido a "absorvê-lo simultânea e instantaneamente".

Segundo McLuhan, nós hoje estaríamos experimentando o auge dessa terceira etapa. A cultura audiovisual-eletrônica, segundo ele, deve ser definida não tanto pelos conteúdos que veicula, mas principalmente pela forma de veiculação. Daí o autor formular sua sentença famosa: "os meios são as mensagens" (The medium is the message, 1967). McLuhan está claramente afirmando que o ato de comunicar é mais representativo da nossa cultura ocidental contemporânea do que os fatos em si mesmos comunicados. Importa menos o que se comunica e mais como se comunica. É uma filosofia da forma, e não do conteúdo. Inclusive, pode-se notar que McLuhan chega ao seu pressuposto: toda cultura se define por suas bases tecnológicas, no caso, as tecnologias comunicacionais-informacionais ${ }^{2}$.

Resumidamente, Marshall McLuhan constrói sua teoria da cultura e da comunicação a partir da idéia da "natureza tecnológica" do homem³ ${ }^{3}$ É aí que faz mais sentido pensar nos "meios de comunicação como extensões do homem", pois prolongariam o alcance de nossos sentidos, para além das nossas potências biológicas naturais. Para McLuhan, estamos hoje imersos em um fluxo audiovisual intenso, que nos determina mais pela forma (seus significantes audiovisuais) do que pelos conteúdos veiculados (seus significados racionalizáveis). É a partir dessa teoria mcluhaniana que passo agora à análise da cultura audiovisual atual, tal como a formula o teórico norte-americano Todd Gitlin - numa espécie de atualização, um tanto crítica, dos conceitos de McLuhan.

\section{Todd Gitlin e a torrente de significantes audiovisuais}

Todd Gitlin (1943-) é um professor de Sociologia e de Jornalismo, no Ph.D. de Communications da Columbia University (New York, EUA). Autor de uma obra que agencia as teses mcluhanianas com uma visão 
mais crítica, Gitlin teoriza sobre a cultura audiovisual-eletrônica, mas sem abandonar a análise das novas formas de consenso pelos significantes midiáticos atuais.

Para Todd Gitlin, o paradoxo contemporâneo está no fato de que o inesperado (extra-ordinário) surge com tanta freqüência que chega a ser esperado (ordinário). O inesperado em si já é esperado. Estamos de prontidão, no limite... e estressados até o desgaste total ${ }^{4}$. Se o mundo pressiona, a leitura deve ser feita aos pedaços. Mais horas de "lazer" significam, na prática da imanência feroz, mais coisas para se fazer ao mesmo tempo agora.

Os moduladores de afecção e sensação se multiplicaram nas últimas décadas. Contudo, a disponibilidade das mensagens audiovisuais não saciou a fome de imagens e sons - pelo contrário. Quanto mais desses produtos ou serviços temos, mais os usamos; quanto mais os usamos, mais queremos usá-los: esta lógica é semelhante àquela do vício. Para fugirmos do tédio, mergulhamos na torrente. Talvez tenha sido Hollywood que nos tenha ensinado a esperar que a nossa vida tenha música de fundo, intriga amorosa e happy end ${ }^{5}$.

Há hoje uma "economia política da atenção". Os anunciantes pagam para conseguir a atenção dos consumidores potenciais. As empresas de Marketing têm profissionais especializados em planejamento de campanha e em "posicionamento da marca" (na mente do público-alvo). As agências de Publicidade organizam e executam a comunicação que deve chamar a atenção do público-alvo. As empresas jornalísticas atrelaram definitivamente suas notícias às regras do entretenimento e da diversão - sabe-se hoje que a melhor maneira de se vender notícias é inseri-las, juntamente com seu público, num ambiente de entretenimento e diversão. Se "vender afetos" serve para todas as atividades, até para o Jornalismo, está-se falando de um Mercado irredutivelmente Semiocapitalista.

Em realidade, o desejo de todos é o de sobressair em meio à bagunça de afetos e signos. Essa torrente sem sentido é aquele zumbido das mídias, produto do frenesi da competição ao modo capitalista. Para chamar a atenção, a empresa - com seu trabalho imaterial - deverá atrelar sua proposta a um "estado de espírito" qualquer, que dependerá do tipo de produto ou serviço que ela vende, e como dirá Todd Gitlin (GITLIN, 2003: 84): "Estados de espírito têm valor monetário. Organizá-los é um bom negócio". Isso é um trabalho imaterial, pois as imagens não sofrem o efeito da gravidade, não se cansam, não têm que ser transportadas por uma maquinaria pesada - (GITLIN, 2003: 156): "Na era do fluxo incessante de imagens, não há angústia social que não possa ser atendida com uma mercadoria, uma moda e uma aparição no noticiário - nenhum dos quais serve para dissolver a angústia".

Antropologicamente, uma "marca" sempre foi o mesmo que um "estigma" (ver Erving Goffman, em Estigma). A maioria das pessoas manifesta sua indiferença quanto a marcar-se com as marcas da hora ${ }^{6}$. Usar uma marca pode ser uma declaração, uma confissão pública, um cartão de visita. No planeta marcado pelo espetáculo do consumo, até mesmo os que se declaram "revolucionários" se marcam com marcas. O Semiocapitalismo tenta ser um "Capitalismo sem atritos" - poder-se-ia dizer, uma produção de indistinção 
entre vida e Mercado, entre viver e consumir. Segundo Neal Gabler (apud GITLIN, 2003: 190), "a vida se tornou um espetáculo encenado para as mídias”. Daí a relevância, mesmo e principalmente hoje, das teses de Guy Debord.

O imensurável, o incalculável, o não-quantificável - ou seja, o afeto (que também não é "qualidade”, mas “intensidade") - foi primeiramente mapeado por bancos-de-dados cada vez mais precisos (levantamento imaterial de um campo de saber) e, agora, foi tornado fonte de lucro por empresas deste Capitalismo da sociedade de Controle (exercício imaterial de uma relação de poder). A distração é justamente aquilo que o novo trabalhador precisa para que volte a trabalhar mais "intensamente" (alegre, pimpão, empolgado, doando mais a sua alma $)^{7}$.

Somos "reenergizados", "recarregados", “estimulados" pelo entretenimento comercializado. Talvez por isso sejamos "cine-addicteds" (isto é, "viciados em movimentos físicos"), ou mais: "celeraddicteds" (isto é, "dromo-addicteds", "viciados em velocidade ou corrida", como poderia preferir Paul Virilio). Detectado por Virilio em 1977 e relembrado por Gitlin em 2003, um dos prazeres da rapidez é “deixar os lentos para trás”.

Algumas pessoas usam estimulantes químicos (drogas licitas e/ou ilícitas); outros usam estimulantes alimentícios (energéticos, suplementos) - mas quase todos usam os estimulantes afetivo-sígnicos (as diversas tecnologias midiáticas - os $\mathrm{MCM}$ e as $\mathrm{NTIC}^{8}$ ). Com as mídias, vivemos momentos fantásticos: ao mesmo tempo em êxtase (fora de nós) e integrados (unidos num só). Fala Todd Gitlin: "Abra envelopes falando ao telefone, leia e-mail enquanto espera o 'atendimento ao consumidor', jogue um videogame enquanto assiste à novela - o leitor está familiarizado com essas tentativas de esticar o tempo, de transformar seqüência em quase simultaneidade". (GITLIN, 2003: 145)

O problema é que diversão não é apenas diversão - o "infotenimento" do atual Jornalismo. Ela nos distrai dos assuntos políticos mais relevantes e urgentes, ensi(g)nando-nos a tolerância, a complacência, o consenso e a anestesia. E o fato de que se produz sem cessar o "novo", a "novidade", não contradiz esta idéia - apenas a confirma: não deveríamos confundir o "novo" (um produto ou serviço - elemento "reformista", conservador e comercializável) com o "inovador” (elemento distintivo da verdadeira Arte - elemento revolucionário e nãocomercializável). "Omo dupla ação" não é “inovador” (não requer muita criatividade), com relação ao "Omo", mas é apenas "novo" (mais um, somente atualizado).

Segundo Gitlin, Robert Putnam demonstrou que aqueles que deixam a TV ligada como "pano de fundo", em casa, revelaram-se os mais desligados da vida política. A torrente é por demais atarefada. Assim, o poder não precisa se esforçar para combater mobilizações políticas - enfraquece-as para controlá-las. Nossa sorte é que o sentido revolucionário ainda não desapareceu por completo. Mas ele tem sido caluniado pela grande mídia (capitalista).

A "capitalização-midiatização" do entretenimento é uma das maiores fontes de recursos financeiros dos EUA. No ano de 1999, o conjunto das mídias de Massa - cinema, TV, rádio, Publicidade, impressos e 
programas para computador - foi a principal atividade de suas exportações, responsável por um valor de quase 80 bilhões de dólares. Só os programas de computador (incluindo aí o entretenimento de videogames e pornografia digital) respondem por 50 bilhões deste total (GITLIN, 2003).

A força de penetração do Semiocapitalismo nas regiões locais é algo de se notar com algum susto. Como se poderia entender que habitantes da cidade de Hong-Kong usem alegremente pelas ruas, cotidianamente, camisetas-outdoors que gritam: "Sinto-me Coca-Cola"? Este problema não é simplesmente de Política, de cultura ou de economia; é um problema de ontologia política. Insistimos: o que estamos nos tornando? Qual a "abertura ontológica" do leque de virtualidades que nos afetam, e que têm a capacidade mínima de se atualizarem em nós, individual e coletivamente ${ }^{9}$ ? Outro exemplo - mais uma demonstração da gravidade da coisa - é fornecido por Gitlin:

"Ou a experiência de um repórter de televisão alemão enviado à Sibéria para filmar a vida nativa que, depois de voar de Moscou e viajar durante dias de barco, ônibus e jipe, chega perto do mar Ártico, onde vive uma tribo de tungusianos conhecidos dos etnólogos por seus rituais com peles de urso. No armazém da comunidade está um avô com o netinho nos joelhos. $\mathrm{O}$ avô está vestido com roupas tungusianas tradicionais. O netinho usa na cabeça um boné de beisebol com aba para trás”. (GITLIN, 2003: 241)

O Planeta inteiro, apesar das diferenças locais específicas, está unido - como numa "aldeia global" mcluhaniana - por um tipo estranho de sensibilidade convergente. Essa sensibilidade padronizada aceita, como seus "desvios-padrão", gostos e comportamentos divergentes - os bancos-de-dados estão aí para mapeá-los e ganhar dinheiro em cima deles também. Na realidade imanente do contexto do Semiocapitalismo, a nossa potência de "sermos afetados pelo mundo" definirá conseqüentemente (mediada pelo desejo) a nossa potência de "afetarmos o mundo". E para nos ajudar a compreender isso, a ontologia política de Spinoza (século XVII) ainda é fundamental.

Mas não se pense que o Império (Capitalista e midiático) nos impõe seus signos à força, "de fora”. Ele nos ataca "por dentro", afetivamente. O cidadão, já tornado público, realmente "quer" esses signos - e os "quer" com toda força. No entanto, o problema é mais complexo: depois de algumas gerações sendo gradativamente acostumadas aos afetos e signos divertidamente capitalistas, como não esperar que hoje as pessoas se declarem "amantes" desses afetos e signos? É uma pedagogia perversa, essa do Controle semiocapitalista.

Na juventude, a sensação de vinculação social já ultrapassa o mero “consumo imediato". Ela atingiu o próprio ritmo da sociedade e, portanto, dos indivíduos: as pessoas adentram o fluxo semiocapitalista e ali tentam "navegar" ("Navegar é preciso", mas também "urgente"), enquanto administram o risco de ficarem "à deriva”. Como dizia Gitlin, parodiando McLuhan, o fluxo é a mensagem:

"Num mundo tão indiscriminadamente brutal, em que suportar seus ataques e atritos ou mesmo sentir medo é uma vitória, ele [o filme de ação] oferece o prazer da transcendência niilista. (...) O que têm em comum 
[os diversos gêneros de filmes de ação] é o choque cinético (...) No mundo inteiro, esses filmes e os videogames e música heavy metal a eles comparáveis domesticam a brutalidade. (...) São os Sistemas Dolby do ruído emocional em meio à confusão e à inconclusividade da vida cotidiana. Para levar a platéia a sentir intensamente sem riscos, ministram doses homeopáticas de choque”. (GITLIN, 2003: 260-261 e 263)

A violência não é gratuita, na mídia. Assim como os cigarros são veículos para fornecer nicotina, o entretenimento midiático é um veículo para fornecer doses controladas de adrenalina - e, como diz Gitlin, são até mesmo resenhados como se fossem produtos farmacêuticos! Os desenhos animados baseados na Disney exercem o trabalho imaterial da "produção de adorabilidade", da reinvenção cotidiana da simpatia capitalizada, da amabilidade vulnerável, pelo Controle "criativo" da dosagem de afetos e signos. Esses são os "novos recursos para o bom adestramento". O sucesso da Disney é que ela sempre ofereceu afetos otimistas -

reconfortantes, aconchegantes. É claro que, assim, haveria demanda por parte do público. O fato de a Disney roteirizar a ridicularização de toda autoridade também seduziu milhões, dando margem e força a um tipo midiático de Totalitarismo ${ }^{10}$.

O excesso imaterial nas telas, telinhas e telões apenas adorna, como suporte significante, aquilo que é verdadeiramente comunicado: o próprio fluxo imaterial, que nos chega pelos signos carregados de afetos capitalísticos (de integração e consenso) - em Hollywood, diz-se que “o dinheiro todo está na tela”. O que o Semiocapitalismo nos ensi(g)na é a vivermos "naturalmente" com o capital. A idéia que nos chega por afetos e signos midiáticos é: queremos mais mídia, durante mais tempo. Os conteúdos pouco nos importam - importa mesmo é estarmos juntos na torrente de significantes audiovisuais, a qual se comunica com nosso corpo.

\section{Conclusão: império da forma sobre o conteúdo}

A Pós-Modernidade não tem, como pretendia Baudrillard, um "gosto pelo irreal". Provavelmente o problema é muito mais complexo do que isso. Umberto Eco pôde falar de um "desejo frenético do quase-real" (Travels in hyperreality - apud GITLIN, 2003: 35). O que esperamos dessas imagens é que amplifiquem a vida, que a intensifiquem, ao serem "melhores" do que o real, mais vívidas, mais "garantidas". Talvez esperemos das mídias que elas sejam "extensões da vida”. Essa busca da "intensificação" que diverte, da "intensidade potente", provavelmente foi e é tornada possível por nossa "sensação de impotência de existir". Gitlin critica (GITLIN, 2003: 62): "Os divertimentos encorajam as pessoas a sentir de forma intensificada, a regozijar-se com sentimentos familiares, mas também a experimentar alguns novos, para sentir-se, sem riscos, uma outra pessoa".

Como Gitlin afirmaria (GITLIN, 2003: 57): “Assim se evidencia o indivíduo moderno, um ator que é, também, em meio expediente, um aventureiro e buscador de estímulos que tenta freneticamente encontrar-se abandonando-se. Este indivíduo paradoxal está preparado para as mídias ilimitadas”. 
Contudo, o homem não suporta a distância entre sua potência e a realização dela ${ }^{11}$. Assim como o consumidor, pensando-se soberano, não suporta a distância entre o seu desejo e a satisfação do seu desejo. É aí que o Capitalismo semiótico "captura e incorpora" as potências, ofertando-lhes imagens e sons, mas tornandoas politicamente impotentes: se estamos "preparados" para a mídia ilimitada, se temos direito a ela, por quê não nos entregarmos desde já? Diz Todd Gitlin (GITLIN, 2003: 39): "Sentimos - não temos dúvida - que temos o direito de ser abordados por nossas mídias, direito de desfrutá-las, direito de aceitar em nossa sala os rostos que escolhemos e de entrar em inúmeros mundos, de fluir com eles".

Se o neoliberalismo defende o "direito de informar", o individualismo defende o "direito de estar informado". A fome encontra a vontade de comer, e tudo parece se encaixar. O "direito de ir embora" fundiuse, confundiu-se ou tornou-se o "direito de estar em outro lugar" - ou melhor, a "obrigação de circular". O risco da "informação total" é o de ela se tornar "totalitária" - ou seja, sem lado de fora, sem outra possibilidade de vida. Todd Gitlin explica esta idéia:

“Hoje nenhum espaço está a salvo. Colocam-se anúncios nas costas das poltronas de avião, à altura dos olhos em mictórios, atrás das portas dos cubículos dos banheiros femininos. (...) Qualquer um que tenha uma tela ou uma superfície quer alugá-la - a lateral de um ônibus ou de uma bomba de gasolina, o teto e os lados de um táxi, até mesmo suas calotas”. (GITLIN, 2003: 92-93)

Se não temos a potência que gostaríamos de ter, buscamo-la na selvageria dos fluxos sígnicos, os quais, sem percebermos, modulam nossos afetos, numa cadeia de pequenas afecções alegres seguidas de pequenas afecções tristes... e assim por diante ${ }^{12}$. Por estarmos imersos hoje na torrente das mídias, somos afetados por signos de alegria e de tristeza numa variação contínua que, por se fazer cada vez mais veloz, nos impede que experimentemos cada afecção, seja de horror, seja de júbilo. Sem essa experiência, como é que poderemos pensar na coletividade?

A variação velocíssima de estímulos afetivos, via signos midiáticos, exaure as potências ontológicas e políticas dos sujeitos contemporâneos. Diz nosso autor (GITLIN, 2003: 64): "Mas, na verdade, precisamente esta riqueza e este colorido de impressões tão apressadas são apropriados para a necessidade de estímulo dos nervos superexcitados e exaustos". A partir disso, podemos então nos perguntar novamente: o que é que estamos nos tornando? Essa questão é claramente ontológica, mas não menos política. Como demonstração, selecionamos mais um trecho do livro do Professor Gitlin:

"Num amontoado de letreiros, cada um convidativo à sua própria maneira elétrica, um luminoso em especial pode provocar um arrepio de encantamento, um formigamento de prazer ou uma reação irritadiça ou atordoada - um pequeno surto de sentimento - seguido por um rastro fugidio de brilho antes de sumir, deixando, caso o anunciante tenha sorte, uma recordação instável de sentimento afetado pelo resto de uma imagem. Contudo, assim que passar a sensação, o transeunte voltará a passar pela cidade em estado de prontidão - ou indiferença”. (GITLIN, 2003: 69) 
Finalmente, então, sugerimos ser fundamental e urgente uma análise crítica da atual cultura das torrentes eletrônicas (cada vez mais digitais), inserindo-a no seu contexto socioeconômico global (do Semiocapitalismo imaterial e cognitivo). Para isso, acreditamos que as obras de Marshall McLuhan, ontem, e de Todd Gitlin, hoje, sejam de grande relevância, já que multiplicam os questionamentos sobre a nossa contemporaneidade comunicacional-informacional. 


\section{Referências bibliográficas}

ARENDT, Hannah. As origens do totalitarismo (vol. III). Rio de Janeiro: Documentário, 1979.

ATEM, Guilherme Nery. O pensamento atacado: comunicação, política e produção de apatia. Rio de Janeiro: E-papers, 2001.

. Comunicação, trabalho imaterial e política: controle dos afetos e administração das semioses. Rio de Janeiro: Tese (doutorado) - UFRJ / Escola de Comunicação / Programa de PósGraduação em Comunicação e Cultura, 2004.

BENJAMIN, Walter. A obra de arte na era de sua reprodutibilidade técnica. In: Obras escolhidas: magia e técnica, arte e política (Vol. 1). São Paulo: Brasiliense, 1994 (7ª ed.).

BRIGGS, Asa; BURKE, Peter. Uma história social da mídia: de Gutenberg à Internet. Rio de Janeiro: Jorge Zahar Editor, 2004.

COCCO, Giuseppe; GALVÃO, Alexander Patez; SILVA, Gerardo (Orgs.). Capitalismo cognitivo: trabalho, redes e inovação. Rio de Janeiro: DP\&A, 2003.

COHN, Gabriel. O meio é a mensagem: análise de McLuhan. In: COHN, Gabriel (Org.). Comunicação e indústria cultural. São Paulo: Editora Nacional, 1977.

DEBORD, Guy. A sociedade do espetáculo (seguido de Comentários sobre a sociedade do espetáculo). Rio de Janeiro: Contraponto, 1997.

DELEUZE, Gilles. Spinoza - philosophie pratique. Paris: Les Éditions de Minuit, 1981. . Conversações. Rio de Janeiro: Ed.34, 1996 (1ª reimpressão).

GITLIN, Todd. Mídias sem limite. Rio de Janeiro: Civilização Brasileira, 2003.

GOFFMAN, Ervin. Estigma. Rio de Janeiro: Zahar Editores, 1980 ( $3^{\text {a }}$ edição).

GORZ, André. L’immatériel - connaissance, valeur et capital. Paris: Galilée, 2003.

HALL, Stuart. A identidade cultural na pós-modernidade. Rio de Janeiro: DP\&A, 2002 (7 $7^{\mathrm{a}}$ ed.).

HOHLFELDT, Antonio; MARTINO, Luiz C.; FRANÇA, Vera Veiga (Orgs.). Teorias da comunicação: conceitos, escolas e tendências. Petrópolis: Vozes, 2002 ( $2^{\mathrm{a}}$ ed.).

KELLNER, Douglas. A cultura da mídia - Estudos Culturais: identidade e política entre o moderno e o pósmoderno. Bauru: Edusc, 2001.

LAZZARATO, Maurizio; NEGRI, Antonio. Trabalho imaterial: formas de vida e produção de subjetividade. Rio de Janeiro: DP\&A, 2001.

MARTÍN-BARBERO, Jesús. Dos meios às mediações: comunicação, cultura e hegemonia. Rio de Janeiro:

Editora UFRJ, 2001 ( $2^{\mathrm{a}}$ ed.).

MATTELART, Armand; MATTELART, Michèle. História das teorias da comunicação. São Paulo: Loyola, 
1999.

MC LUHAN, Marshall. The medium is the message. New York: Bantam Books, 1967.

Os meios de comunicação como extensões do homem. São Paulo: Cultrix, 1969.

NEGRI, Antonio. Infinitude da comunicação / Finitude do desejo. In: PARENTE, André (Org.). Imagem-

Máquina: a era das tecnologias do virtual. Rio de Janeiro: Ed.34, 1993.

RAMONET, Ignácio. Conclusão: informar-se é cansativo. In: A tirania da comunicação. Petrópolis: Vozes, 2001 ( $2^{\mathrm{a}}$ edição).

ROSENTHAL, Raymond (Org.). McLuhan: Pro and Con. United States of America: Penguin Books, 1968.

SINGER, Ben. Modernidade, hiperestímulo e o início do sensacionalismo popular. In: CHARNEY, Leo;

SCHWARTZ, Vanessa (Orgs.). O cinema e a invenção da vida moderna. São Paulo: Cosac \& Naify, 2001.

SPINOZA, Baruch. Ética. Coleção Os Pensadores. São Paulo: Nova Cultural, 1997.

VIRILIO, Paul. Velocidade e política. São Paulo: Estação Liberdade, 1996.

WOLF, Mauro. Teorias das comunicações de massa. São Paulo: Martins Fontes, 2003.

\footnotetext{
${ }^{1}$ Doutor em Comunicação e Cultura (ECO-UFRJ). Professor Adjunto (Depto. de Comunicação Social) da Universidade Federal Fluminense.gui.nery@globo.com

${ }^{2}$ Os mais críticos da obra de McLuhan podem afirmar que o argumento do referido autor é circular, não demonstrando nada: encontraria, ao final da explicação, o que já pressupunha no seu início. Críticos benjaminianos dirão que as teses de McLuhan (da percepção moldada pela tecnologia) já teriam sido trabalhadas por Walter Benjamin, antes e melhor. Entretanto, não iremos enveredar por tal controvérsia no espaço deste artigo.

${ }^{3}$ Percebe-se que, em McLuhan, natureza e cultura não são opostas, mas complementares e co-determinantes. Por um lado, a natureza incluiria a cultura, ou seja, a cultura seria uma parte integrante da natureza. Por outro lado, só teríamos acesso ao mundo natural através das lentes da cultura e da tecnologia em que estamos inseridos. Pierre Lévy também parte deste pressuposto.

${ }^{4}$ Percebe-se aí a influência dos estudos sociológicos da Escola de Chicago, do início do século XX, os quais partiram das teorizações do alemão Georg Simmel: Park, Burgess, McKendrick.

5 Ver o clássico livro de Edgar Morin, Cultura de massas no século XX - o espírito do tempo (vol. 1 - neurose).

${ }^{6}$ Nunca poderemos esquecer o poema Eu, etiqueta, de Carlos Drummond de Andrade.

${ }^{7}$ Esta questão já foi trabalhada por Siegfried Kracauer, da Escola de Frankfurt.

${ }^{8}$ MCM: Meios de Comunicação de Massa. NTIC: Novas Tecnologias de Informação e Comunicação.

9 Sabemos que Umberto Eco diz que "a variabilidade da interpretação é a lei invariável da comunicação de massas" (Travels in hyperreality, de 1967, apud Gitlin). Contudo, pensamos que essa "variabilidade" não revela uma "liberdade" real, ontológica, mas apenas determina o leque de possibilidades pré-determinadas ("interpretantes", ou "semas") pelo "emissor". Essa "variabilidade" tem a função de seduzir o público e, portanto, está perfeitamente integrada à lógica do Semiocapitalismo.

${ }^{10} \mathrm{O}$ fato de Hannah Arendt assinalar que o Totalitarismo surge quando a autoridade se desfaz não significa que ela, e nem nós neste texto, defendamos a autoridade ou o Autoritarismo (que, aliás, são diferentes). Apenas queremos nomear o inominável, mascarado de "Democracia de Mercado".

${ }^{11} \mathrm{O}$ maior problema ético, hoje, é o da confusão entre a potência e o direito. Diz-se: "se eu tenho a potência ou capacidade de fazer algo, por que não fazê-lo?" (a própria ciência age assim). Da mesma forma, confunde-se hoje consciência moral com moralismo: qualquer tentativa de análise crítica é logo batizada de "moralista". Como pode intelectuais abrirem mão de seu papel fundamental, a visão crítica? Sinal dos tempos...

${ }^{12}$ No século XVII, o filósofo Baruch Spinoza fundou sua Ética nas modulações das afecções: alegria, tristeza e desejo.
} 